\title{
Optimal management of glenohumeral osteoarthritis
}

This article was published in the following Dove Press journal:

Orthopedic Research and Reviews

\section{Chase B Ansok \\ Stephanie J Muh}

Department of Orthopaedic Surgery, Henry Ford Hospital, Detroit, MI, USA

Correspondence: Stephanie J Muh Department of Orthopaedic Surgery, Henry Ford Hospital, 2799 W. Grand Blvd., CFP-642, Detroit, MI 48202, USA

Tel + I 3 I3 5873854

Email smuhl@hfhs.org
Abstract: Glenohumeral osteoarthritis (OA) is defined as progressive loss of articular cartilage, resulting in bony erosion, pain, and decreased function. This article provides a gross overview of this disease, along with peer-reviewed research by experts in the field. The pathology, diagnosis, and classification of this condition have been well described. Treatment begins with non-operative measures, including oral and topical anti-inflammatory agents, physical therapy, and intra-articular injections of either a corticosteroid or a viscosupplementation agent. Operative treatment is based on the age and function of the affected patient, and treatment of young individuals with glenohumeral OA remains controversial. Various methods of surgical treatment, ranging from arthroscopy to resurfacing, are being evaluated. The roles of hemiarthroplasty, total shoulder arthroplasty, and reverse shoulder arthroplasty are similarly reviewed with supporting data.

Keywords: glenohumeral, osteoarthritis, hyaluronic acid, hemiarthroplasty, total shoulder arthroplasty

\section{Introduction Epidemiology}

Osteoarthritis (OA) is the commonest joint disease worldwide and affects over 25 million people in the US alone. ${ }^{1}$ The disease carries a profound societal, economical, and psychological burden, particularly in light of the nation's aging population. ${ }^{2}$ The glenohumeral joint is the third most common large joint to be affected following the knee and hip. ${ }^{3}$ While the true prevalence of glenohumeral OA is difficult to ascertain, population-based studies have demonstrated that $16.1 \%-20.1 \%$ of adults older than 65 years have radiographic evidence of glenohumeral OA.,5 Other well-established risk factors for glenohumeral OA include female sex, Caucasian race, and obesity. Secondary causes of glenohumeral OA include avascular necrosis, infectious or crystalline arthropathy, prior trauma such as dislocation, and prior surgery. With regard to post-traumatic $\mathrm{OA}$, the largest review to date evaluated 570 patients with a history of instability and found that $19.7 \%$ had radiographic evidence of glenohumeral OA at a mean follow-up of 12 years. ${ }^{6}$ Arthrogenic factors include age at time of dislocation, presence of a rotator cuff tear, and presence of bony defects of either the glenoid or humerus. By contrast, rheumatoid arthritis is characterized by earlier onset of disease, more rapid progression, and more severe osteopenia than primary or post-traumatic OA. It affects the shoulder in more than $90 \%$ of patients with greater than 5 years of rheumatoid disease. ${ }^{7}$ Glenohumeral OA must be differentiated from rotator cuff arthropathy, which has an identifiable precipitating cause and a distinct treatment algorithm. 


\section{Natural history}

The rate of progression of primary glenohumeral OA is impossible to predict, with cartilage loss occurring over months to years. It is important to note that cartilage loss, whether visualized radiographically or arthroscopically, does not necessarily correlate with patient symptoms. ${ }^{8}$ No study to date has evaluated the progression of arthritic changes in the shoulder in either asymptomatic or symptomatic patients. A 15-year cohort study following the progression of radiographic knee OA found an annual rate of disease progression of $2.8 \% .{ }^{9}$ It is unclear if the shoulder demonstrates a similar course. Unfortunately, there are no known interventions that demonstrably reverse or slow the natural history of early OA.

Over time, OA will result in worsening pain and stiffness, yielding functional limitations and decreased quality of life. These limitations are typically most noticeable with overhead activities and in external rotation. Patients often complain of difficulty falling asleep or awaking often due to night pain. The impact of these factors on quality of life and psychological health is well described; Cho et al reported rates of depression and anxiety of $15.2 \%$ and $19.5 \%$ in a cohort of patients with glenohumeral OA. ${ }^{10}$ Systematic reviews have clearly demonstrated improvements in health-related quality of life following treatment. ${ }^{11}$

\section{Pathology}

There are numerous biomechanical and biochemical processes involved in the development and progression of glenohumeral OA. The progression of degenerative joint disease should be contrasted with the natural process of aging. With age, the collagen content of cartilage is unchanged, and the collagen becomes less hydrated and more permeable. ${ }^{12}$ In
OA, increased activities of collagenase and matrix metalloproteinases are associated with increased water content, disorganization of the collagen framework, and breakdown of protein proteoglycan content. ${ }^{13}$ The pathology of OA at the molecular level is the subject of intense research focus and remains incompletely understood. Nuclear factor kappa B (NFKB) promotes the expression of inflammatory cytokines such as interleukin- $1 \beta$ and tumor necrosis factor- $\alpha$, both of which can induce apoptosis of chondrocytes. ${ }^{14}$ This can occur independently or in conjunction with formation of cytotoxic reactive oxygen species created by mechanical stress. ${ }^{15}$

The glenohumeral joint is a diarthrodial joint that is highly dependent on surrounding soft tissues for stability. ${ }^{16}$ Nonetheless, articular congruity is an important factor with regard to joint stability. The hyaline cartilage of the humeral head is thickest at its center, while the glenoid has thicker cartilage at its periphery, most notably at the anteroinferior aspect. ${ }^{17}$ These differences in cartilage thickness, as well as the glenoid labrum, yield a congruent joint. However, thinner areas are more susceptible to cartilage injury and degeneration, resulting in exposed subchondral bone. In the setting of OA, there is a progressive increase in the subchondral bone plate thickness, a modification in the architecture of subchondral trabecular bone, and formation of osteophytes at the joint margins (Figure 1). In the glenohumeral joint, the posterior glenoid and central aspect of the humeral head are typically the first areas to get affected. ${ }^{18}$

Joint incongruity results in abnormal loading of articular cartilage, exacerbating the degeneration of chondrocytes. Cartilage defects have severely limited capacity for healing, as articular cartilage is poorly vascularized, and few undifferentiated cell populations are present near the articular surface. ${ }^{19}$

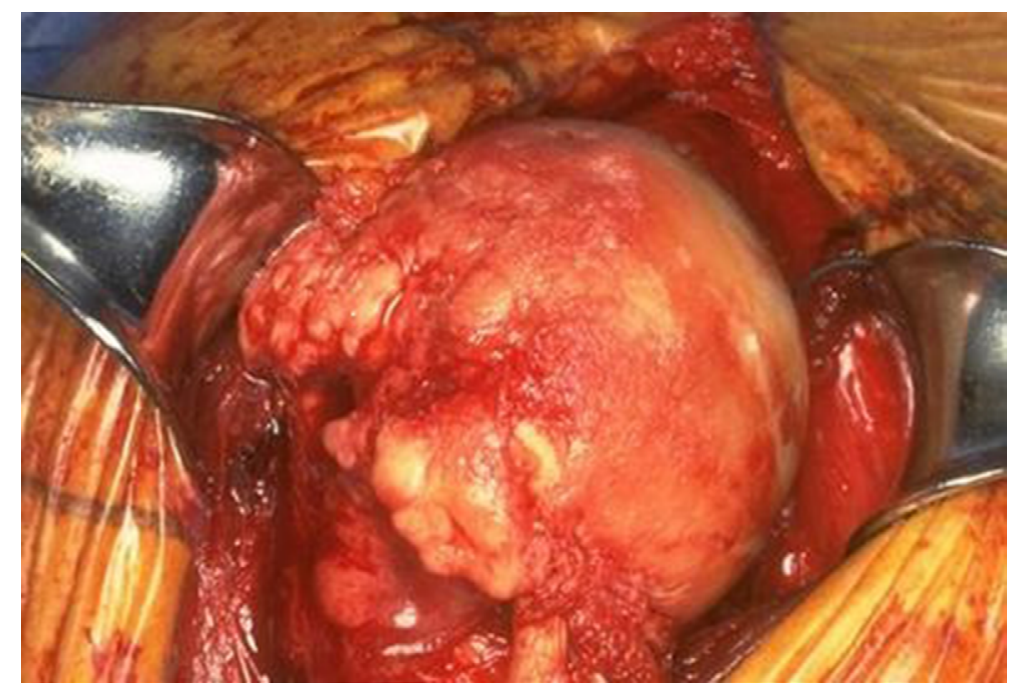

Figure I Advanced osteoarthritis of the humeral head. 
In the setting of glenohumeral OA, capsular thickening and contraction may result in a pronounced internal rotation deficit, furthering the eccentric erosion of the posterior glenoid. As described by Neer, the posterior wear is often associated with a posteriorly subluxated humeral head. ${ }^{20}$ When compared to healthy subjects, patients with glenohumeral OA have an increased incidence of glenoid retroversion. ${ }^{21}$

\section{Diagnosis}

In 1974, Neer described primary glenohumeral OA as a limitation in shoulder movement, loss of joint space, the presence of humeral head osteophytes, and the absence of rotator cuff tear. $^{22}$ It remains critically important to different OA from rotator cuff arthropathy. Patient history often provides vital clues. Pain from OA is often localized posteriorly and deep within the joint. It is typically associated with night pain, stiffness, and functional limitations. ${ }^{23}$ Patients with a history of trauma to the shoulder or systemic inflammatory disease may have earlier onset of disease.

Physical examination should exclude etiologies of pain outside the shoulder and attempt to identify other pathology within the shoulder, such as tendinosis and bursitis. Neck pain, pain radiating down the arm, and pain with provocative maneuvers such as Spurling's test suggest a cervical source of pain. A thorough neck and neurovascular examination should always be performed. Pain at the greater tuberosity, weakness, or lag signs suggest rotator cuff disease. Impingement and OA are not mutually exclusive diagnoses, but impingement should be identified nonetheless. ${ }^{24}$ Active and passive range of motion of the shoulder should be assessed and compared. Maneuvers such as Neer's impingement sign, cross-body adduction, and the Hawkins-Kennedy sign should be included in a physical exam. ${ }^{25}$

Radiographs are the keystone to diagnosing and staging glenohumeral OA. As already described, joint space narrowing and posterior glenoid wear are common findings.
The presence of subchondral sclerosis and osteophytes from the humeral head, often described as a "goat's beard", is an anticipated finding as well (Figure 2). ${ }^{26}$ Advanced imaging is rarely necessary for diagnosis but can provide useful information for staging, identification of concomitant labral or rotator cuff pathology, and preoperative planning.

\section{Classification}

The Walch et al classification was proposed in 1999 following a multicenter study of 151 shoulders in 141 patients. ${ }^{27}$ This scheme utilized plain radiographs and 2-dimensional computed tomography. The classification includes five wear patterns of the glenoid. Type A1 describes a centered humeral head with minor glenoid erosion, whereas type A2 describes major central glenoid erosion. The goal of this classification is to define glenohumeral pathology and aid surgeons in preoperative planning; it does not provide information regarding functional performance. Type $\mathrm{C}$ refers to a dysplastic glenoid with at least $25^{\circ}$ of retroversion. Interobserver and intraobserver reliability varied in studies over the following years; values ranged from 0.37 to 0.60 for interobserver reliability and from 0.34 to 0.87 for intraobserver reliability. ${ }^{28,29}$

In 2016, Bercik et al proposed a modification to this classification system after performing three-dimensional CT scans on 129 shoulders with primary glenohumeral OA (Figure 3). ${ }^{30}$ This new system redefines an A2 glenoid, stating that a line drawn from the anterior to posterior rim of the glenoid must transect the humeral head. It also includes a B3 glenoid, which is described as a posteriorly subluxated humeral head with monoconcavity, posterior wear, and at least $15^{\circ}$ of retroversion. Lastly, it includes a type D glenoid, described as any level of glenoid anteversion, or anterior humeral head subluxation of greater than $40 \%$. They reported interobserver and intraobserver reliabilities of 0.703 and 0.882 , respectively. The most commonly identified types were A2, B2, and B3.

\section{A}

B

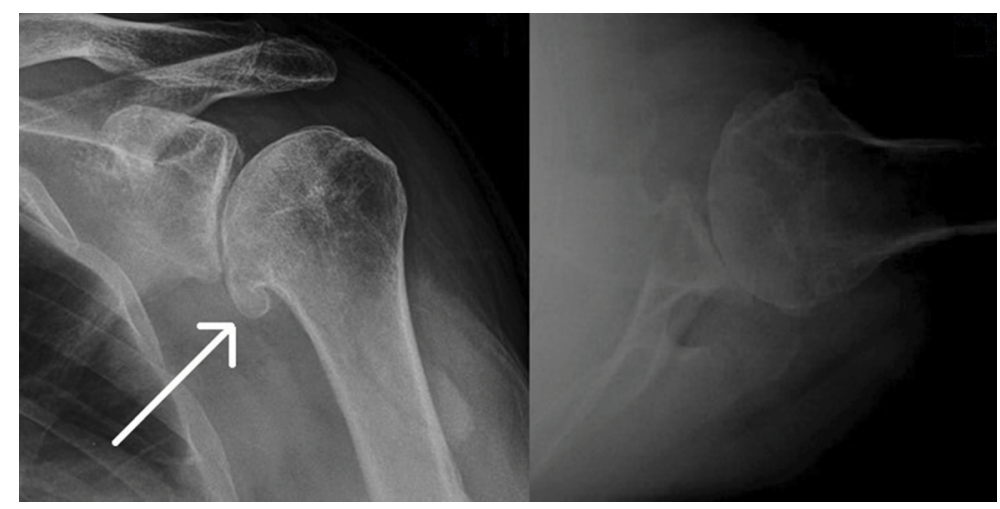

Figure 2 Advanced osteoarthritis with prominent inferior osteophyte.

Notes: (A) Grashey view; (B) axillary view. The arrow points to the prominent interior osteophyte. 


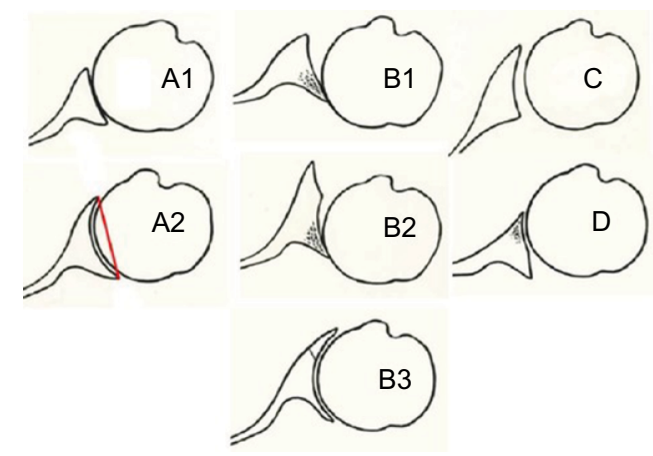

Figure 3 Modified Walch classification.

Notes: Al:Centered humeral head with minor erosion; A2: centered humeral head, major central erosion; BI: posterior subluxated head without bony erosion; B2: posterior subluxated head, posterior erosion with biconcavity of the glenoid; B3: monoconcavity with retroversion > I5 degrees; C: dysplastic glenoid with at least $25^{\circ}$ of retroversion regardless of erosion; D: glenoid anteversion and/or anterior subluxation. Reprinted from Publication J Shoulder Elbow Surg, 25 /I0, Bercik MJ, Kruse K 2nd, Yalizis M, Gauci MO, Chaoui J, Walch G, A modification to the Walch classification of the glenoid in primary glenohumeral osteoarthritis using threedimensional imaging., 160I-1606, Copyright (2016), with permission from Elsevier..$^{30}$

\section{Treatment}

\section{Nonoperative treatment}

The first step of management of primary glenohumeral OA is, with very few exceptions, nonoperative treatment. Acetaminophen in dosages of 3-4 grams daily has been demonstrated to be both safe and effective. While no randomized controlled trials have demonstrated a significant benefit of using non-steroidal anti-inflammatory drugs to treat shoulder pain, $50 \%-67 \%$ of patients can expect improvement in their pain. ${ }^{23,31}$ Other trials have shown improvement with use of oral prednisolone. ${ }^{32} \mathrm{COX}-2$ inhibitors have not been shown to be more efficacious. ${ }^{33}$ As always, the side effect profile of these medications must be taken into consideration. Most notably, patients with a history of gastrointestinal bleeding or renal disease should discuss use with their primary care physicians or specialists. Oral corticosteroid treatment is not recommended by the American College of Rheumatology. ${ }^{34}$ Topical formulations of these medications have not been well studied. Topical capsaicin, a transient receptor vanilloid-1 receptor antagonist, has been evaluated in treatment of $\mathrm{OA}$ of the knee and hand and found to be more effective than placebo with few side effects. ${ }^{35}$ Its role in management of glenohumeral OA has not been studied.

Intra-articular injections remain one of the most commonly utilized nonoperative treatments for OA. Of particular interest are the roles of corticosteroids (typically methylprednisolone) and hyaluronic acid, for which there are multiple formulations. Of note, while use of hyaluronic acid in the shoulder has been approved by the European Medicines Agency since 2007, the Federal Drug Administration has approved its use only in knees. ${ }^{36}$ Merolla et al compared intra-articular methylprednisolone to Hylan G-F 20 and found that though both groups had significant improvement in pain at 1 month; only the hyaluronic acid had sustained pain relief at 6 months. ${ }^{37}$ The largest randomized control trials have demonstrated a decrease in short-term pain scores. Blaine et al evaluated 660 patients with glenohumeral OA and found a threefold decrease in pain in a group receiving Hyalgan ${ }^{\circledR}$ (Fidia Pharma USA Inc, Florham Park, NJ, USA) compared to placebo at 26-week follow-up $(p=0.003) \cdot{ }^{38} \mathrm{~A}$ second trial of 300 patients with chronic shoulder pain found a statistically insignificant decrease in pain $(p=0.112)$ in a group receiving Supartz ${ }^{\circledR}$ (Bioventus LLC, Durham, NC, USA) compared to placebo. However, in a subgroup of patients with glenohumeral OA as the source of shoulder pain, intra-articular hyaluronic acid was found to be superior $(p=0.028) .{ }^{39}$ No randomized clinical trials have assessed shoulder function following intra-articular injections, though numerous small prospective trials, such as those by Brander et al, have shown sustained improvement in the simple shoulder test at 6 months $(p=0.001) .{ }^{40}$ A prospective trial by Di Giacomo and De Gasperis comparing 30 patients receiving intra-articular hyaluronic acid to 30 receiving placebo found that active forward elevation improved by $18^{\circ}$ compared to $7.8^{\circ}$, active external rotation improved by $7.6^{\circ}$ compared to $4.5^{\circ}$, and Constant scores improved by 13.4 points compared to 8.2 points; these findings were all statistically significant $(p<0.05) .{ }^{41}$

These injections are not without risks or side effects. Transient suppression of the hypothalamic-pituitary-adrenal axis by average of $21.5 \%$ has been demonstrated, persisting for up to 72 hours. ${ }^{42}$ In patients with diabetes mellitus, hyperglycemia and increased ophthalmologic pressures have been well documented. The rate of septic arthritis varies greatly in the literature, but has cited from 1 in 3,000 to 1 in 50,000 cases. ${ }^{43}$ With regard to hyaluronic acid, less frequent injections with higher molecular weight preparations appear to have a lower rate of septic arthritis, though this finding was demonstrated in knees rather than the glenohumeral joint. ${ }^{44,45}$

Numerous studies have elucidated the difficulty in accurately administering intra-articular injections to the glenohumeral joint. ${ }^{46}$ Sethi et al found that only $26.8 \%$ of anteriorly placed injections were successfully placed in the glenohumeral joint, ${ }^{47}$ and Hegedus et al demonstrated successful intra-articular injections in $52.4 \%$ of their subjects. ${ }^{48}$ However, later studies stand in contrast to these findings, with Rutten et al demonstrating success with an ultrasound-guided approach in $94 \%$ of their subjects. ${ }^{49}$ Most recently, Kraeutler et al described a technique in which a point $1.0-1.5 \mathrm{~cm}$ 
lateral to the coracoid process and at the anterior joint line is identified, and a 21 gauge 1.5 inch needle is passed at a $45^{\circ}$ angle relative to the floor. ${ }^{50}$ With this technique, success was demonstrated in $93.3 \%$ of their 75 patients. These studies demonstrate the need for adherence to a replicable anatomic approach or use of ultrasound to effectively insert a needle intra-articularly.

Physical therapy is often incorporated into a multidisciplinary nonoperative treatment plan. There are no agreed upon treatment models with regard to intensity or duration of therapy. A cognitive approach with supervised physical activity has been suggested. ${ }^{51}$ No studies have evaluated the efficacy of physical therapy as an isolated treatment. As part of a multimodal treatment plan, sustained improvements in pain and function were seen in a 3-year follow-up in a study of 129 patients aged 65 years and older conducted by Guo et al. ${ }^{52}$ Surgeons must take into the patient's physiologic and psychologic health when creating a treatment plan for OA.

\section{Operative management} Non-arthroplasty techniques

The operative treatment of glenohumeral OA is reserved for patients who have failed the aforementioned conservative treatments. In elderly or low-demand patients, total shoulder arthroplasty (TSA) is a reliable and highly successful procedure. However, concerns regarding implant longevity and decreased activity levels have led surgeons to pursue joint-preserving procedures in younger and more active patients. ${ }^{53,54}$ Mitchell et al have reported good early outcomes with their technique of comprehensive arthroscopic management. ${ }^{55}$ This arthroscopic technique, described in detail by Millet et al, involves extensive capsular release, osteoplasty of the humeral head, treatment of identified SLAP lesions or biceps tenosynovitis, and axillary nerve neurolysis when scarring or compression is noted. ${ }^{56} \mathrm{~A}$ review of 107 shoulders at a 2-year follow-up demonstrated that while $15.8 \%$ of these patients underwent TSA within 2 years, the remainder reported high satisfaction. ${ }^{57}$ Unfortunately, similar success has not been reported by all groups. In a cohort of 33 patients, Skelley et al found that pain relief and range of motion were not sustained at 1-year follow-up, and $42.4 \%$ of their cohort had undergone arthroplasty within 9 months. ${ }^{58}$

Isolated cartilage lesions in the shoulder are rare, and they are unlikely to be a predominant source of pain. When present, however, they can be treated in a similar fashion to cartilage lesions elsewhere in the body. So-called palliative treatment-lavage or debridement-is reserved for lesions identified incidentally at the time of arthroscopic management of other conditions about the shoulder. ${ }^{59}$ In general, the size of the lesion dictates treatment. Small, superficial osteochondral defects can be treated with microfracture and debridement. ${ }^{60}$ Cameron et al reported $88 \%$ of patients experiencing significant pain relief over an average of 28 months; ${ }^{61}$ Gross et al found good or excellent results in $78 \%$ of patients at 30 months. ${ }^{62}$

\section{Resurfacing}

While restorative treatments such as autologous cartilage implantation and autograft transfers have been described, these procedures have limited utility in the shoulder and the long-term results are unknown. Focal prosthetic resurfacing has been studied more extensively. The goal of these operations is to provide pain relief and maintain function while allowing for conversion to TSA at a later date. Ideal candidates for these procedures are young people with minimal glenoid wear and intact rotator cuffs..$^{63}$ Patients with avascular necrosis and maintained peripheral articular congruity are also candidates. ${ }^{64}$ Levy et al reported on cementless surface replacement arthroplasty with 54 patients under the age of 50 years. ${ }^{65}$ They found profound increases in Constant scores (mean increase $11.5 \%-71.8 \%, p<0.0001$ ), with a survival rate of $81.6 \%$ at a minimum of 10 years. Iagulli et al also had good outcomes in a cohort of 36 patients aged 55 years and younger; mean visual analog score (VAS) decreased from 7.5 to $1.3(p<0.0001)$ and American Shoulder and Elbow Surgeon (ASES) scores improved from 29.8 to $87.7(p<0.001){ }^{66}$ Humeral head inlay arthroplasties have also revealed good short-term results, with Wiater and Fabing reporting a 95\% rate of good or excellent results at 8 months in a cohort of 62 patients. ${ }^{67}$ The longest follow-up study, reported by Sweet et al, showed a mean improvement in ASES scores from 24.1 to 78.8 at an average follow-up of 32.7 months. ${ }^{68}$

The role of biologic resurfacing has remained controversial since its inception in the late 1980s. Initially described with an autogenous fascia lata graft by Burkhead and Hutton, ${ }^{69}$ biologic resurfacing intends to avoid metal-onbone contact and minimize glenoid erosion and pain. Other interposition arthroplasties have made use of Achilles tendon allograft and lateral meniscal allograft; no significant differences have been reported between these agents. ${ }^{70}$ Krishnan et al reported their results using anterior capsule, autogenous fascia lata, and Achilles tendon allograft. ${ }^{71}$ They noted 50\% excellent results overall, with poorer results in patients in whom anterior capsule was used. Wirth reported significant improvement in ASES, VAS, and Simple Shoulder Test scores in patients who underwent lateral meniscus allograft in 
18-month follow-up, with $94 \%$ of patients stating they would undergo the procedure again. ${ }^{72}$ This was supported by Bois et al, who found similar results with meniscal allograft in 30 patients monitored for an average of 3 years. ${ }^{73}$

Strauss et al identified 41 patients who had undergone biologic resurfacing of the glenoid in conjunction with humeral head arthroplasty and compared them to those without biologic resurfacing and found relatively high failure rates $(30 \%)$ in both groups. ${ }^{74}$ Both groups had similar pain and function at 2.5-year follow-up. Conversely, Somerson et al have had promising results with a ream-and-run procedure in which the glenoid is resurfaced without an arthroplasty. ${ }^{75}$ At a mean follow-up of 3 years, there were 2 revisions in 30 shoulders, and an average increase in Simple Shoulder Test scores from 5 to 10 . In this cohort, the procedure was reserved for those with glenoid retroversion and posterior displacement of the humeral head, and the authors caution a steep learning curve.

\section{Hemiarthroplasty and TSA}

The modern total shoulder prosthesis was developed by Neer in 1974, and current designs continue to use a cemented allpolyethylene glenoid component. ${ }^{76}$ Numerous authors have documented the efficacy of anatomic TSA. It is one of the most rapidly growing procedures in the US, with over a fourfold increase in revisions and fivefold increase in primaries from 2001 to $2010 .^{77,78}$ A 1982 review by Neer et al reported high satisfaction in all but 4 patients from a cohort of 194 shoulders managed with a minimally constrained TSA at a minimum 2-year follow-up. ${ }^{79}$ In 1984, Cofield reviewed 73 TSAs implanted with the Neer prosthesis at 2- to 6.5-year follow-up. Active abduction improved by $44^{\circ}$, to an average of $120^{\circ}$. In the absence of postoperative complications, the results were predictably good. ${ }^{80}$ In a follow-up study, Kelly et al reviewed 89 TSAs at a minimum follow-up of 5 years with similar results in pain and function. Prosthetic survival was $93 \%$ at 10 -year follow-up and $87 \%$ after 15 years. ${ }^{81}$

Once controversial, hemiarthroplasty (use of a stemmed humeral component without a glenoid component) has been shown to be inferior to TSA with regard to both pain and function. ${ }^{82}$ TSA allows for a better fulcrum for motion, better strength, and decreased pain. At two-year follow-up, significantly improved Constant scores, forward elevation, and pain scores in TSA were reported by Edwards et al in 2003. ${ }^{83}$ Moreover, revision rates for hemiarthroplasty may exceed $30 \%$ within 10 years and often have unsatisfactory results, with Sperling et al reporting 60\% unsatisfactory rate compared to only $10 \%$ excellent rate. ${ }^{80}$ The conversion of a failed hemiarthroplasty as a salvage procedure has also been shown to have very low rates of satisfaction. Carroll et al reported a $47 \%$ unsatisfactory rate at 5-year follow-up. ${ }^{84}$ The largest meta-analysis to date, by Radnay et al, pooled nearly 50 years of studies comparing hemiarthroplasty to TSA and identified a total of 1,952 patients. ${ }^{85}$ The pooled outcomes showed vastly improved pain and range of motion in the TSA and a far lower revision rate (6.5\% vs. $10.2 \%)$. Indications for stemmed humeral hemiarthroplasty has generally been replaced by reverse TSA, and indications are now limited to those without glenoid bone stock to support a prosthesis. ${ }^{86}$ Younger patients still benefit from TSA. ${ }^{87}$ Sowa et al followed a cohort of 21 patients with a mean age of 55 years and an average follow-up of 13 years. Patients maintained high Constant scores and satisfaction, though two patients had undergone revision. ${ }^{88}$

Repair of the subscapularis is of paramount importance to prevent anterior instability. Terrier et al showed that a deficient subscapularis induces an upward migration of the humeral head, an eccentric contact pattern, and higher stress within the cement. ${ }^{89}$ Numerous biomechanical studies have assessed repair techniques; no significant differences in strength have been identified between subscapularis tenotomy or subscapularis peel. ${ }^{90,91}$ While lesser tuberosity osteotomy shows greater biomechanical strength, this has not been shown to have improved clinical outcomes. ${ }^{92}$ Jandhyala et al reported that both tenotomy and osteotomy groups had similar clinical function, ${ }^{93}$ consistent with findings by Ahmad et al. ${ }^{94}$ Subscapularis-sparing approaches have been attempted, though as of yet the complication rate remains unacceptably high. ${ }^{95}$

\section{Reverse TSA}

In patients with severe rotator cuff deficiency, either fullthickness tearing or fatty infiltration, anatomic TSA may not be a viable treatment option. Reports of primary repair of the supraspinatus at time of arthroplasty have had good results with function and pain, though these patients must be carefully selected. Simone et al reported on 33 patients over a 15-year period with a mean follow-up of 4.7 years; VAS decreased from 4.7 to 1.7 , although their complication rate was $15 \% .{ }^{96}$ The use of reverse TSA has rapidly increased following the development of the Grammont reverse prosthesis and its medialized center of rotation. ${ }^{97}$ Rotator cuff arthropathy is a distinct entity that must be differentiated from primary glenohumeral OA. Reverse prostheses have been used in the management of glenohumeral OA, particularly in elderly patients with biconcave glenoids or severe glenoid 


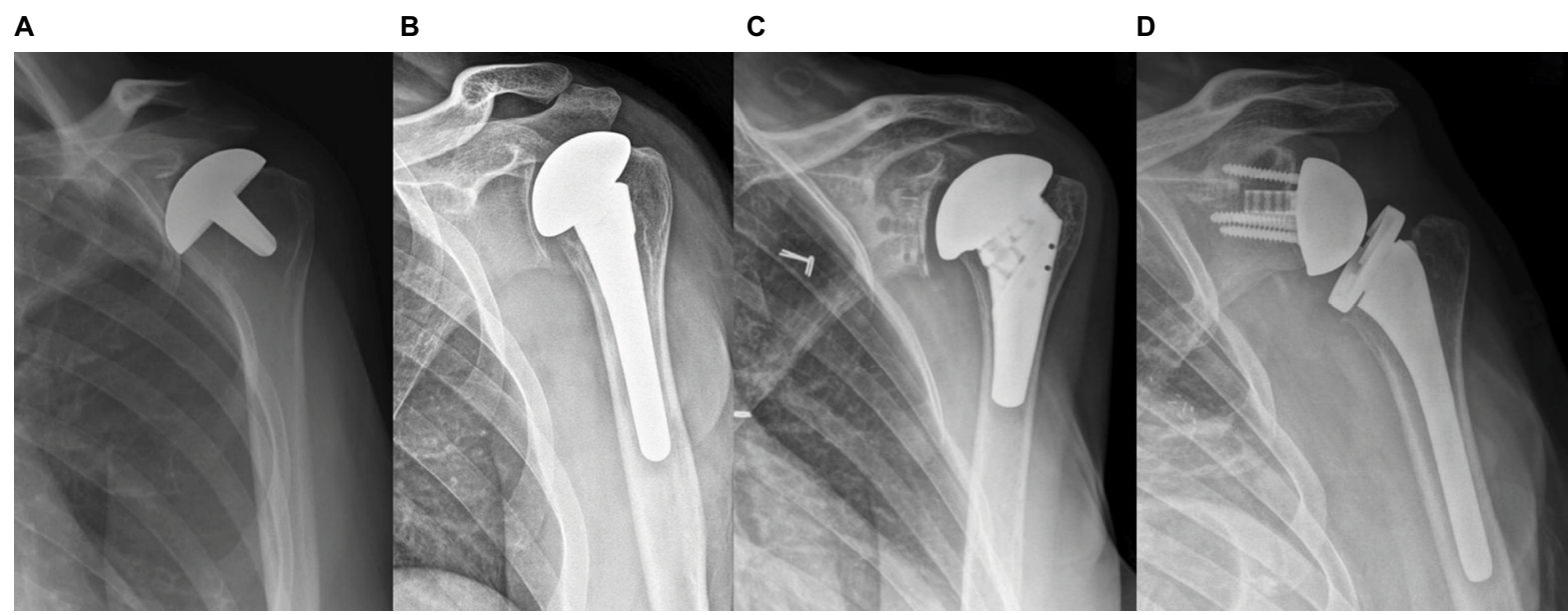

Figure 4 Various glenohumeral arthroplasties.

Note: (A) Humeral inlay arthroplasty; (B) stemmed humeral hemiarthroplasty; (C) total shoulder arthroplasty; (D) reverse total shoulder arthroplasty.

bone loss. ${ }^{98}$ In a cohort of 27 patients and mean follow-up of 54 months, Mizuno et al reported a Constant score increase from 31 to 76 points, with only 1 case of glenoid loosening. ${ }^{99}$ Figure 4 shows radiographic demonstrations of four distinct glenohumeral prostheses.

\section{Complications}

Shoulder arthroplasty has been proven to be a safe and highly effective procedure, with complication rates similar to or lower than that of hip and knee arthroplasty. ${ }^{100}$ The major complications of shoulder arthroplasty include periprosthetic fracture, infection, instability, rotator cuff lesions, loosening of the glenoid component, and neurologic injuries. ${ }^{101}$ The rate of periprosthetic fractures is between $1.6 \%$ and $2.3 \%$ and are often associated with cortical thinning due to osteolysis and osteopenia. Infection rates vary across the literature, but have been reported as high as $4 \% .{ }^{102}$ Prosthetic joint infections of the shoulder are managed much the same as other arthroplasties, often necessitating placement of an antibiotic spacer and two-stage revision. Anterior instability occurs in $0.9 \%-1.8 \%$ of cases, typically due to failure of subscapularis repair. ${ }^{103}$ Aseptic glenoid loosening is uncommon and may not require revision if asymptomatic. Removal of a painful loose component and reaming of the glenoid (leaving a hemiarthroplasty) has been described. ${ }^{104}$ Complication rate and poor outcomes have been shown to have an inverse relationship with surgeon volume. ${ }^{105}$

\section{Summary}

The management of glenohumeral OA begins with a comprehensive evaluation of the patient. Conservative management includes physical therapy, anti-inflammatory medications, and intra-articular injections. Operative treatment is dictated by patient factors, with younger, more active patients benefitting from non-arthroplasty techniques or those with minimal bone resection. Hemiarthroplasty of the humeral head has largely been replaced by modern TSA, with reverse shoulder arthroplasty as an increasingly utilized treatment in cases of glenoid biconcavity or rotator cuff disease. Optimal management of young patients with end-stage disease remains an important topic of for investigation. Surgeons should be aware of the common complications and pitfalls of arthroplasty.

\section{Disclosure}

The authors report no conflicts of interest in this work.

\section{References}

1. Neogi T, Zhang Y. Epidemiology of osteoarthritis. Rheum Dis Clin North Am. 2013;39(1):1-19.

2. Litwic A, Edwards MH, Dennison EM, Cooper C. Epidemiology and burden of osteoarthritis. Br Med Bull. 2013;105:185-199.

3. Zhang Y, Jordan JM. Epidemiology of osteoarthritis. Clin Geriatr Med. 2010;26(3):355-369.

4. Kobayashi T, Takagishi K, Shitara H, et al. Prevalence of and risk factors for shoulder osteoarthritis in Japanese middle-aged and elderly populations. J Shoulder Elbow Surg. 2014;23(5):613-619.

5. Oh JH, Chung SW, Oh CH, et al. The prevalence of shoulder osteoarthritis in the elderly Korean population: association with risk factors and function. J Shoulder Elbow Surg. 2011;20(5):756-763.

6. Buscayret F, Edwards TB, Szabo I, Adeleine P, Coudane H, Walch G. Glenohumeral arthrosis in anterior instability before and after surgical treatment: incidence and contributing factors. Am J Sports Med. 2004;32(5):1165-1172.

7. Chen AL, Joseph TN, Zuckerman JD. Rheumatoid arthritis of the shoulder. J Am Acad Orthop Surg. 2003;11(1):12-24.

8. Chillemi C, Franceschini V. Shoulder osteoarthritis. Arthritis. 2013;2013:370231

9. Leyland KM, Hart DJ, Javaid MK, et al. The natural history of radiographic knee osteoarthritis: a fourteen-year population-based cohort study. Arthritis Rheum. 2012;64(7):2243-2251.

10. Cho CH, Song KS, Hwang I, Coats-Thomas MS, Warner JJP. Changes in psychological status and health-related quality of life following total shoulder arthroplasty. J Bone Joint Surg Am. 2017;99(12):1030-1035. 
11. Carter MJ, Mikuls TR, Nayak S, Fehringer EV, Michaud K. Impact of total shoulder arthroplasty on generic and shoulder-specific healthrelated quality-of-life measures: a systematic literature review and meta-analysis. J Bone Joint Surg Am. 2012;94(17):e127.

12. Miller MD, Hart JA. Review of Orthopaedics. Philadelphia, PA: Saunders / Elsevier; 2008.

13. Moskowitz RW. Osteoarthritis: Diagnosis and Medical/Surgical Management. Philadelphia, PA: Wolters Kluwer Health/Lippincott Williams \& Wilkins; 2007

14. Woo CH, Eom YW, Yoo MH, et al. Tumor necrosis factor-alpha generates reactive oxygen species via a cytosolic phospholipase A2-linked cascade. J Biol Chem. 2000;275(41):32357-32362.

15. Henrotin YE, Bruckner P, Pujol JP. The role of reactive oxygen species in homeostasis and degradation of cartilage. Osteoarthritis Cartilage. 2003;11(10):747-755.

16. Soslowsky LJ, Flatow EL, Bigliani LU, Mow VC. Articular geometry of the glenohumeral joint. Clin Orthop Relat Res. 1992;(285):181-190.

17. Fox JA, Cole BJ, Romeo AA, et al. Articular cartilage thickness of the humeral head: an anatomic study. Orthopedics. 2008;31(3):216.

18. Menge TJ, Boykin RE, Byram IR, Bushnell BD. A comprehensive approach to glenohumeral arthritis. South Med J. 2014;107(9):567-573.

19. Sabatini M, Pastoureau P, De Ceuninck F. Cartilage and Osteoarthritis: Cellular and Molecular Tools. Totowa, NJ: Humana Press; 2004.

20. Goss TP, Owens BD. Fractures of the scapula. In: Rockwood CA Jr, Matsen FA, editors. The Shoulder. 4th ed. Vol. 1. Philadelphia, PA: Saunders/Elsevier; 2009.

21. Fardet L, Messow M, Maillefert JF, Dougados M. Primary glenohumeral degenerative joint disease: factors predisposing to arthroplasty. Clin Exp Rheumatol. 2003;21(1):13-18.

22. Neer CS 2 nd. Replacement arthroplasty for glenohumeral osteoarthritis. J Bone Joint Surg Am. 1974;56(1):1-13.

23. Millett PJ, Gobezie R, Boykin RE. Shoulder osteoarthritis: diagnosis and management. Am Fam Physician. 2008;78(5):605-611.

24. Andrews JR. Diagnosis and treatment of chronic painful shoulder: review of nonsurgical interventions. Arthroscopy. 2005;21(3): 333-347.

25. Blaine TA. Diagnosis, pathology, and nonsurgical treatment of painful shoulder. Arthroscopy. 2006;22(1):117-118; author reply 118-119.

26. Kircher J, Kuerner K, Morhard M, Krauspe R, Habermeyer P. Agerelated joint space narrowing independent of the development of osteoarthritis of the shoulder. Int J Shoulder Surg. 2014;8(4):95-100.

27. Walch G, Badet R, Boulahia A, Khoury A. Morphologic study of the glenoid in primary glenohumeral osteoarthritis. J Arthroplasty. 1999;14(6):756-760.

28. Habermeyer P, Magosch P, Weiß C, et al. Classification of humeral head pathomorphology in primary osteoarthritis: a radiographic and in vivo photographic analysis. J Shoulder Elbow Surg. 2017; 26(12):2193-2199.

29. Nowak DD, Gardner TR, Bigliani LU, Levine WN, Ahmad CS. Interobserver and intraobserver reliability of the Walch classification in primary glenohumeral arthritis. J Shoulder Elbow Surg. 2010;19(2):180-183.

30. Bercik MJ, Kruse K 2nd, Yalizis M, Gauci MO, Chaoui J, Walch G. A modification to the Walch classification of the glenoid in primary glenohumeral osteoarthritis using three-dimensional imaging. J Shoulder Elbow Surg. 2016;25(10):1601-1606.

31. Sinha I, Lee M, Cobiella C. Management of osteoarthritis of the glenohumeral joint. Br J Hosp Med (Lond). 2008;69(5):264-268.

32. Wenham CY, Hensor EM, Grainger AJ, et al. A randomized, double-blind, placebo-controlled trial of low-dose oral prednisolone for treating painful hand osteoarthritis. Rheumatology (Oxford). 2012;51(12):2286-2294.

33. Gordo AC, Walker C, Armada B, Zhou D. Efficacy of celecoxib versus ibuprofen for the treatment of patients with osteoarthritis of the knee: a randomized double-blind, non-inferiority trial. J Int Med Res. 2017;45(1):59-74.
34. Hochberg MC, Altman RD, April KT, et al; American College of Rheumatology. American College of Rheumatology 2012 recommendations for the use of nonpharmacologic and pharmacologic therapies in osteoarthritis of the hand, hip, and knee. Arthritis Care Res (Hoboken). 2012;64(4):465-474.

35. Guedes V, Castro JP, Brito I. Topical capsaicin for pain in osteoarthritis: a literature review. Reumatol Clin. Epub 2016 Aug 26. Spanish [with English abstract].

36. Kwon YW, Eisenberg G, Zuckerman JD. Sodium hyaluronate for the treatment of chronic shoulder pain associated with glenohumeral osteoarthritis: a multicenter, randomized, double-blind, placebo-controlled trial. J Shoulder Elbow Surg. 2013;22(5):584-594.

37. Merolla G, Sperling JW, Paladini P, Porcellini G. Efficacy of Hylan G-F 20 versus 6-methylprednisolone acetate in painful shoulder osteoarthritis: a retrospective controlled trial. Musculoskelet Surg. 2011;95(3):215-224.

38. Blaine T, Moskowitz R, Udell J, et al. Treatment of persistent shoulder pain with sodium hyaluronate: a randomized, controlled trial. A multicenter study. J Bone Joint Surg Am. 2008;90(5):970-979.

39. Colen S, Geervliet P, Haverkamp D, Van Den Bekerom MP. Intraarticular infiltration therapy for patients with glenohumeral osteoarthritis: a systematic review of the literature. Int J Shoulder Surg. 2014;8(4):114-121.

40. Brander VA, Gomberawalla A, Chambers M, Bowen M, Nuber G. Efficacy and safety of hylan G-F 20 for symptomatic glenohumeral osteoarthritis: a prospective, pilot study. PM R. 2010;2(4):259-267.

41. Di Giacomo G, De Gasperis N. The role of hyaluronic acid in patients affected by glenohumeral osteoarthritis. J Biol Regul Homeost Agents. 2015;29(4):945-951.

42. Gross C, Dhawan A, Harwood D, Gochanour E, Romeo A. Glenohumeral joint injections: a review. Sports Health. 2013;5(2):153-159.

43. Werner BC, Cancienne JM, Burrus MT, Griffin JW, Gwathmey FW, Brockmeier SF. The timing of elective shoulder surgery after shoulder injection affects postoperative infection risk in Medicare patients. $J$ Shoulder Elbow Surg. 2016;25(3):390-397.

44. Noël E, Hardy P, Hagena FW, et al. Efficacy and safety of Hylan G-F 20 in shoulder osteoarthritis with an intact rotator cuff. Open-label prospective multicenter study. Joint Bone Spine. 2009;76(6):670-673.

45. Silverstein E, Leger R, Shea KP. The use of intra-articular hylan G-F 20 in the treatment of symptomatic osteoarthritis of the shoulder: a preliminary study. Am J Sports Med. 2007;35(6):979-985.

46. Esenyel CZ, Ozturk K, Demirhan M, et al. Accuracy of anterior glenohumeral injections: a cadaver study. Arch Orthop Trauma Surg. 2010;130(3):297-300

47. Sethi PM, Kingston S, Elattrache N. Accuracy of anterior intra-articular injection of the glenohumeral joint. Arthroscopy. 2005;21(1):77-80.

48. Hegedus EJ, Zavala J, Kissenberth M, et al. Positive outcomes with intra-articular glenohumeral injections are independent of accuracy. J Shoulder Elbow Surg. 2010;19(6):795-801.

49. Rutten MJ, Collins JM, Maresch BJ, et al. Glenohumeral joint injection: a comparative study of ultrasound and fluoroscopically guided techniques before MR arthrography. Eur Radiol. 2009;19(3):722-730.

50. Kraeutler MJ, Cohen SB, Ciccotti MG, Dodson CC. Accuracy of intra-articular injections of the glenohumeral joint through an anterior approach: arthroscopic correlation. J Shoulder Elbow Surg. 2012;21(3):380-383.

51. Macías-Hernández SI, Morones-Alba JD, Miranda-Duarte A, et al. Glenohumeral osteoarthritis: overview, therapy, and rehabilitation. Disabil Rehabil. 2017;39(16):1674-1682.

52. Guo JJ, Wu K, Guan H, et al. Three-year follow-up of conservative treatments of shoulder osteoarthritis in older patients. Orthopedics. 2016;39(4):e634-e641.

53. Henry P, Razmjou H, Dwyer T, Slade Shantz JA, Holtby R. Relationship between probability of future shoulder arthroplasty and outcomes of arthroscopic debridement in patients with advanced osteoarthritis of glenohumeral joint. BMC Musculoskelet Disord. 2015;16:280. 
54. van der Meijden OA, Gaskill TR, Millett PJ. Glenohumeral joint preservation: a review of management options for young, active patients with osteoarthritis. Adv Orthop. 2012;2012:160923.

55. Mitchell JJ, Warner BT, Horan MP, et al. Comprehensive arthroscopic management of glenohumeral osteoarthritis: preoperative factors predictive of treatment failure. Am J Sports Med. 2017;45(4):794-802.

56. Millett PJ, Horan MP, Pennock AT, Rios D. Comprehensive Arthroscopic Management (CAM) procedure: clinical results of a joint-preserving arthroscopic treatment for young, active patients with advanced shoulder osteoarthritis. Arthroscopy. 2013;29(3):440-448.

57. Van Thiel GS, Sheehan S, Frank RM, et al. Retrospective analysis of arthroscopic management of glenohumeral degenerative disease. Arthroscopy. 2010;26(11):1451-1455.

58. Skelley NW, Namdari S, Chamberlain AM, Keener JD, Galatz LM, Yamaguchi K. Arthroscopic debridement and capsular release for the treatment of shoulder osteoarthritis. Arthroscopy. 2015;31(3):494-500.

59. McCarty LP 3rd, Cole BJ. Nonarthroplasty treatment of glenohumeral cartilage lesions. Arthroscopy. 2005;21(9):1131-1142.

60. Hünnebeck SM, Magosch P, Habermeyer P, Loew M, Lichtenberg S. Chondral defects of the glenohumeral joint: long-term outcome after microfracturing of the shoulder. Obere Extrem. 2017;12(3):165-170.

61. Cameron BD, Galatz LM, Ramsey ML, Williams GR, Iannotti JP. Non-prosthetic management of grade IV osteochondral lesions of the glenohumeral joint. J Shoulder Elbow Surg. 2002;11(1):25-32.

62. Gross CE, Chalmers PN, Chahal J, et al. Operative treatment of chondral defects in the glenohumeral joint. Arthroscopy. 2012;28(12): 1889-1901.

63. Verstraelen FU, Horta LA, Schotanus MGM, Kort NP, Samijo SK, Jansen EJP. Clinical and radiological results 7 years after Copeland shoulder resurfacing arthroplasty in patients with primary glenohumeral osteoarthritis: an independent multicentre retrospective study. Eur J Orthop Surg Traumatol. Epub 2017 Aug 3.

64. Al-Hadithy N, Furness N, Patel R, et al. Cementless surface replacement hemiarthroplasty for primary glenohumeral osteoarthritis: results of over 5-year follow-up in patients with or without rotator cuff deficiency. Shoulder Elbow. 2015;7(4):237-243.

65. Levy O, Tsvieli O, Merchant J, et al. Surface replacement arthroplasty for glenohumeral arthropathy in patients aged younger than fifty years: results after a minimum ten-year follow-up. J Shoulder Elbow Surg. 2015;24(7):1049-1060.

66. Iagulli ND, Field LD, Hobgood ER, et al. Surface replacement arthroplasty of the humeral head in young, active patients: midterm results. Orthop J Sports Med. 2014;2(1):2325967113519407.

67. Wiater JM, Fabing MH. Shoulder arthroplasty: prosthetic options and indications. J Am Acad Orthop Surg. 2009;17(7):415-425.

68. Sweet SJ, Takara T, Ho L, Tibone JE. Primary partial humeral head resurfacing: outcomes with the HemiCAP implant. Am J Sports Med. 2015;43(3):579-587.

69. Burkhead WZ Jr, Hutton KS. Biologic resurfacing of the glenoid with hemiarthroplasty of the shoulder. J Shoulder Elbow Surg 1995;4(4):263-270.

70. Muh SJ, Streit JJ, Shishani Y, Dubrow S, Nowinski RJ, Gobezie R. Biologic resurfacing of the glenoid with humeral head resurfacing for glenohumeral arthritis in the young patient. J Shoulder Elbow Surg. 2014;23(8):e185-e190.

71. Krishnan SG, Reineck JR, Nowinski RJ, Harrison D, Burkhead WZ Humeral hemiarthroplasty with biologic resurfacing of the glenoid for glenohumeral arthritis. Surgical technique. J Bone Joint Surg Am. 2008;90 Suppl 2 Pt 1:9-19.

72. Wirth MA. Humeral head arthroplasty and meniscal allograft resurfacing of the glenoid. J Bone Joint Surg Am. 2009;91(5):1109-1119.

73. Bois AJ, Whitney IJ, Somerson JS, Wirth MA. Humeral head arthroplasty and meniscal allograft resurfacing of the glenoid: a concise follow-up of a previous report and survivorship analysis. J Bone Joint Surg Am. 2015;97(19):1571-1577.
74. Strauss EJ, Verma NN, Salata MJ, et al. The high failure rate of biologic resurfacing of the glenoid in young patients with glenohumeral arthritis. J Shoulder Elbow Surg. 2014;23(3):409-419.

75. Somerson JS, Neradilek MB, Service BC, Hsu JE, Russ SM, Matsen FA 3rd. Clinical and radiographic outcomes of the ream-and-run procedure for primary glenohumeral arthritis. J Bone Joint Surg Am. 2017;99(15):1291-1304.

76. Singh JA, Sperling J, Buchbinder R, McMaken K. Surgery for shoulder osteoarthritis. Cochrane Database Syst Rev. 2010;(10):CD008089.

77. Schwartz BE, Savin DD, Youderian AR, Mossad D, Goldberg BA. National trends and perioperative outcomes in primary and revision total shoulder arthroplasty: trends in total shoulder arthroplasty. Int Orthop. 2015;39(2):271-276.

78. Day JS, Lau E, Ong KL, Williams GR, Ramsey ML, Kurtz SM. Prevalence and projections of total shoulder and elbow arthroplasty in the United States to 2015. J Shoulder Elbow Surg. 2010;19(8):1115-1120.

79. Neer CS, 2nd, Watson KC, Stanton FJ. Recent experience in total shoulder replacement. J Bone Joint Surg Am. 1982;64(3):319-337.

80. Sperling JW, Cofield RH, Rowland CM. Minimum fifteen-year follow-up of Neer hemiarthroplasty and total shoulder arthroplasty in patients aged fifty years or younger. J Shoulder Elbow Surg. 2004;13(6):604-613

81. Kelly JD Jr, Norris TR. Decision making in glenohumeral arthroplasty. J Arthroplasty. 2003;18(1):75-82.

82. Trofa D, Rajaee SS, Smith EL. Nationwide trends in total shoulder arthroplasty and hemiarthroplasty for osteoarthritis. Am J Orthop (Belle Mead NJ). 2014;43(4):166-172.

83. Edwards TB, Kadakia NR, Boulahia A, et al. A comparison of hemiarthroplasty and total shoulder arthroplasty in the treatment of primary glenohumeral osteoarthritis: results of a multicenter study. J Shoulder Elbow Surg. 2003;12(3):207-213.

84. Carroll RM, Izquierdo R, Vazquez M, Blaine TA, Levine WN, Bigliani LU. Conversion of painful hemiarthroplasty to total shoulder arthroplasty: long-term results. J Shoulder Elbow Surg. 2004;13(6):599-603.

85. Radnay CS, Setter KJ, Chambers L, Levine WN, Bigliani LU, Ahmad $\mathrm{CS}$. Total shoulder replacement compared with humeral head replacement for the treatment of primary glenohumeral osteoarthritis: a systematic review. J Shoulder Elbow Surg. 2007;16(4):396-402.

86. Rasmussen JV, Olsen BS, Al-Hamdani A, Brorson S. Outcome of revision shoulder arthroplasty after resurfacing hemiarthroplasty in patients with glenohumeral osteoarthritis. J Bone Joint Surg Am. 2016;98(19):1631-1637.

87. Raiss P, Aldinger PR, Kasten P, Rickert M, Loew M. Total shoulder replacement in young and middle-aged patients with glenohumeral osteoarthritis. J Bone Joint Surg Br. 2008;90(6):764-769.

88. Sowa B, Bochenek M, Bülhoff M, et al. The medium- and long-term outcome of total shoulder arthroplasty for primary glenohumeral osteoarthritis in middle-aged patients. Bone Joint J. 2017;99-B(7):939-943.

89. Terrier A, Larrea X, Malfroy Camine V, Pioletti DP, Farron A. Importance of the subscapularis muscle after total shoulder arthroplasty. Clin Biomech (Bristol, Avon). 2013;28(2):146-150.

90. Van Thiel GS, Wang VM, Wang FC, et al. Biomechanical similarities among subscapularis repairs after shoulder arthroplasty. J Shoulder Elbow Surg. 2010;19(5):657-663.

91. Van den Berghe GR, Nguyen B, Patil S, et al. A biomechanical evaluation of three surgical techniques for subscapularis repair. $J$ Shoulder Elbow Surg. 2008;17(1):156-161.

92. Schrock JB, Kraeutler MJ, Houck DA, Provenzano GG, McCarty EC, Bravman JT. Lesser tuberosity osteotomy and subscapularis tenotomy repair techniques during total shoulder arthroplasty: a meta-analysis of cadaveric studies. Clin Biomech (Bristol, Avon). 2016;40:33-36.

93. Jandhyala S, Unnithan A, Hughes S, Hong T. Subscapularis tenotomy versus lesser tuberosity osteotomy during total shoulder replacement: a comparison of patient outcomes. J Shoulder Elbow Surg. 2011;20(7):1102-1107. 
94. Ahmad CS, Wing D, Gardner TR, Levine WN, Bigliani LU. Biomechanical evaluation of subscapularis repair used during shoulder arthroplasty. J Shoulder Elbow Surg. 2007;16(3 Suppl):S59-S64.

95. Ding DY, Mahure SA, Akuoko JA, Zuckerman JD, Kwon YW. Total shoulder arthroplasty using a subscapularis-sparing approach: a radiographic analysis. J Shoulder Elbow Surg. 2015;24(6):831-837.

96. Simone JP, Streubel PH, Sperling JW, Schleck CD, Cofield RH, Athwal GS. Anatomical total shoulder replacement with rotator cuff repair for osteoarthritis of the shoulder. Bone Joint J. 2014;96-B(2):224-228.

97. Levy DM, Abrams GD, Harris JD, Bach BR Jr, Nicholson GP, Romeo AA. Rotator cuff tears after total shoulder arthroplasty in primary osteoarthritis: a systematic review. Int J Shoulder Surg. 2016;10(2):78-84.

98. McFarland EG, Huri G, Hyun YS, Petersen SA, Srikumaran U. Reverse total shoulder arthroplasty without bone-grafting for severe glenoid bone loss in patients with osteoarthritis and intact rotator cuff. $J$ Bone Joint Surg Am. 2016;98(21):1801-1807.

99. Mizuno N, Denard PJ, Raiss P, Walch G. Reverse total shoulder arthroplasty for primary glenohumeral osteoarthritis in patients with a biconcave glenoid. J Bone Joint Surg Am. 2013;95(14):1297-1304.
100. Farmer KW, Hammond JW, Queale WS, Keyurapan E, McFarland EG. Shoulder arthroplasty versus hip and knee arthroplasties: a comparison of outcomes. Clin Orthop Relat Res. 2007;455:183-189.

101. Mattei L, Mortera S, Arrigoni C, Castoldi F. Anatomic shoulder arthroplasty: an update on indications, technique, results and complication rates. Joints. 2015;3(2):72-77.

102. Wirth MA, Rockwood CA Jr. Complications of total shoulderreplacement arthroplasty. J Bone Joint Surg Am. 1996;78(4): 603-616.

103. Armstrong A, Lashgari C, Teefey S, Menendez J, Yamaguchi K, Galatz LM. Ultrasound evaluation and clinical correlation of subscapularis repair after total shoulder arthroplasty. J Shoulder Elbow Surg. 2006;15(5):541-548.

104. Venjakob AJ, Reichwein F, Nebelung W. Arthroscopic removal of a polyethylene glenoid component in total shoulder arthroplasty. Arthrosc Tech. 2015;4(2):e149-e152.

105. Singh JA, Ramachandran R. Does hospital volume predict outcomes and complications after total shoulder arthroplasty in the US? Arthritis Care Res (Hoboken). 2015;67(6):885-890.
Orthopedic Research and Reviews

\section{Publish your work in this journal}

Orthopedic Research and Reviews is an international, peer-reviewed, open access journal that focusing on the patho-physiology of the musculoskeletal system, trauma, surgery and other corrective interventions to restore mobility and function. Advances in new technologies, materials, techniques and pharmacological agents are particularly

\section{Dovepress}

welcome. The manuscript management system is completely online and includes a very quick and fair peer-review system, which is all easy to use. Visit http://www.dovepress.com/testimonials.php to read real quotes from published authors. 